\title{
Predictive Direct Torque Control of Switched Reluctance Motor for Electric Vehicles Drives
}

\author{
Reyad Abdel-Fadil ${ }^{1,2 *}$, László Számel ${ }^{1}$ \\ 1 Department of Electric Power Engineering, Faculty of Electrical Engineering and Informatics, Budapest University of Technology \\ and Economics, H-1111 Budapest, Egry József utca 18., Hungary \\ 2 Department of Electrical Engineering, Faculty of Engineering, Aswan University, Aswan, P.O.B. 81528, Egypt \\ * Corresponding author, e-mail: reyad.abdelfadil@vet.bme.hu
}

Received: 30 December 2019, Accepted: 11 February 2020, Published online: 09 July 2020

\begin{abstract}
The electrical drive systems utilized in Electric Vehicles (EVs) applications must be reliable and high performance. To providing these specifications, it is essential to design high-efficiency electric motors and develop high-performance controllers. This study introduces direct torque control of Switched Reluctance Motor (SRM) for electric vehicle applications using Model Predictive Control (MPC) technique. The direct torque control using MPC is proposed to maintain the motor torque and motor speed to tracking desired signals with a satisfactory response. In this study, the MPC algorithm was programmed in C- language, and the simulation tests were performed using a non-linear model of 6/4 - $60 \mathrm{~kW}$ SRM that is fed with the symmetrical converter. The proposed controller was tested under different load conditions to verify the robustness of the controller, as well as at variable speeds to investigate the tracking performance. Thanks to the proposed method, the SRM torque ripples, stator copper losses, and average switching frequency of the power converter can reduce effectively due to applying a cost function that combines multiple objectives. The obtained outcomes show the effectiveness of the suggested approach compared to conventional direct torque control techniques.
\end{abstract}

Keywords

Switched Reluctance Motor, electric vehicles, control techniques, Model Predictive Control, Direct Torque Control, torque ripples

\section{Introduction}

The use of Electric Vehicles (EVs) in transportation in the past decade has become a necessity, therefore increasing their proportion in commercial markets because they provide a substantial solution to pollution and noise problems and reduces petroleum consumption. As it's known, to achieve the best performance EVs, it requires high-efficiency electric motors assisted by high-accuracy controllers. The Switched Reluctance Motor (SRM) is considered one of the electric motors types that can be used to drive the EVs because this motor is economical and has high torque, and it can also operate in wide/high-speed ranges with high efficiency $[1,2]$. The SRM can be used not only in the EVs but also in many other industrial applications such as aircraft applications, power generation using wind turbines, household devices, etc. Although the SRM has many benefits in industrial applications, it has some drawbacks and challenges that have to be overcome, such as its torque ripples, and complex control [3]. The torque ripples problem of the SRM is so complicated and influenced by multiple factors and not easy to overcome. Therefore, much research has been proposed to minimize the torque ripples by using several different torque control techniques and strategies, various techniques such as feed-forward torque control, and Torque Sharing Function (TSF) techniques have been presented in many articles [4-8]. The offline or online calculated current and torque profiles are applied in some proposals to produce a smooth torque, but these methods have relatively low flexibility.

The predictive control is a broad class of controllers that have found relatively modern applications in power converters. The principal feature of predictive control is the use of the system model to predict the future performance of controlled variables. This data is managed by the controller to achieve the optimal actuation and meets predefined optimization criteria [9]. With the help of the MPC technique, the power converter switches signals can be immediately generated without the necessity of a modulator. The significant benefits of predictive control can 
be summarized as this method is very simple and intuitive, also in this strategy, the equation of the controlled variables is generated from the system model. Thanks to the predictive control method, the cascaded structure of the controllers can be easily avoided, as a result, the transient responses of the controller will faster, and the overall performance will be more efficient. The predictive control can be considered a very suitable control technique for electrical machine drive control, due to its simplicity, robustness, and flexibility to include multivariable and constrained nonlinear systems [10]. The straightforward design procedure is considered a significant advantage of this type of controller technique, the designer only needs using a model of the system, and the desired constraints, then a suitable cost function that includes the control objectives can be easily set up [11].

\section{SRM torque control strategies}

The torque control of the SRM can be performed by two main strategies: The first strategy is called Indirect Torque Control (ITC), where complex algorithms or distribution functions are used to adjust the reference current. Then, the current control loop is used to maintain the phases current in tracking the reference signals to produce the required torque. Three subcategories for this strategy can be considered: Open-loop current profiling, Torque Sharing Function (TSF), and Average Torque Control (ATC) $[12,13]$. In contrast, the second strategy called Direct Torque Control (DTC), this strategy does not use the current control loop but uses a simple control scheme with a hysteresis torque controller to reduce the torque ripple. There are three different approaches of the DTC that have been used in previous research: Direct Instantaneous Torque Control (DITC), Advanced Direct Instantaneous Torque Control (ADITC), and Predictive PWM-DIT [14].

The ITC usually uses the TSF to regulate the torque generated by each phase so that the absolute torque able to reach the desired torque value [15]. Four generally TSFs based-on linear, cubic, sinusoidal, and exponential functions can be optimized to reduce the torque ripple [16]. To decide the ideal TSF and to optimize its terms, it is essential to define secondary objectives. For instance, maximized the torque-speed range, minimization of the copper losses, minimization of the peak phase current, or any other secondary objective [17-19]. Moreover, using the non-linear model of the motor, a high-performance TSF is introduced in [18], where the TSF function can be adapted dynamically based on the current operating condition.
In [20], an online nonlinear logical TSF is proposed to minimize the torque ripples and develop drive performance. Nevertheless, these developed TSF proposals with the auxiliary aim have restricted utilization because that algorithms need more time for the controller parameters tuning. Additionally, the TSF requires sizable storage to keep the nonlinear feature $(I, T$, and $\theta)$ or $(\psi, T$, and $\theta)$ for achieving the high-efficiency conversion from torque to current.

The DTC strategy can to some extent overcome the drawbacks of the ITC. The significant merit of the DTC is that torque is directly considered as a control variable and the current control loop not existed. A unique DTC method is introduced in [21], in that work, the authors use the flux linkage to control the electromagnetic torque directly. While in [22], an on-line DITC method has been proposed, by this technique, the switching signals have been generated by comparing the demanded and generated torque using a conventional hysteresis controller. On the other hand, a review of direct torque control of SRM drives for motoring and regenerative braking operating conditions are presented in [23]. Also, the authors in [24] have developed a low-cost bus current detection-based DITC strategy for SRM drives under soft-chopping mode. In [25], the comparative study of DITC and DTFC has been performed, and the results confirm that the efficiency of the DITC system is better than the efficiency in the case of DTFC. The ratios of the energy of three control methods: open-loop control, current chopping control, and DITC have been studied in [26], and the obtained outcomes proved that the DITC technique has a lower energy ratio value. In another context, the DITC algorithm has been compared with the current profiling method with three different TSFs in [27], the comparison outcomes indicate that the response of the DITC is faster than in the case of the TSF, and its implementation is easier. But, to produce torque with very small ripples during the commutation periods, the DITC needs complex switching rules.

Model Predictive Control (MPC) is a suitable strategy to deal with the non-linear magnetic characteristic of SRM, and several strategies based on MPC have been proposed for SRM drive control [28-33]. The contribution in [28] presents MPC for DTC of SRM, in contrast to other strategies that used the model predictive current controller to reduce the phase current ripples and hence reduce the motor torque ripples [29]. Through merging predictive control and discrete space vector modulation, a unique MPC method has been presented in [30] to reduce the SRM's torque ripples, while the introduced scheme 
in [30] achieves a satisfactory performance of closed-loop control using the space vector modulation technique, but it is hard to implement, and this method needs a considerable amount of computational burden for the algorithm execution. In [31], the authors present a general MPC for SRM current control, which takes advantage of the state estimators and a model identification unit according to the on-line inductance surface estimator. Model predictive with Kalman filtering and inductance profile auto-calibration is improved in [32], this scheme tries to solve the problems of the SRM current control. In [33], The authors provided improved finite-state predictive torque control to contribute to solving the torque ripple problem, the proposed method not only tries to solve the torque ripples issue but also it attempts to reduce average switching frequency.

In this study, an enhanced Predictive Direct Instantaneous Torque Control (PDITC) for SRM is introduced to contribute to solving the problem of torque ripples. To predict the next state of the system variables, a discrete-time predictive model has been built through the careful analysis of the non-linearity of the SRM. The proposed algorithm uses an optimized multi-purpose cost function to minimize the torque ripple, reduce copper losses, and decrease the average switching frequency of the power converter. Then, the optimal voltage vector that minimizes the cost function is chosen from all possible voltage vectors and applied to the power converter in the next sampling period. So, the proposed PDITC method not only accurately controls the torque which leads to small ripples, but also minimizes the copper losses and reduces the average switching frequency.

\section{Predictive torque control}

Normally, the main objective in the motor drive control is to control and maintain the machine's torque close to the command signals, which is usually adjusted using the speed controller. There may be additional objectives for the controller, such as reducing phases currents to minimize copper losses and increase the overall efficiency. Furthermore, a finite switching frequency has a limited ability to regulate the torque of a motor, and the very high switching frequency produces more heat in the power converter switches and increases the heat losses. So the optimization of the average switching frequency is considered a further purpose of the controller. Thus, there is a necessary trade-off between realizing minimum torque ripples, operating the controller at the low switching frequency, and improving overall efficiency by reducing copper losses. This trade-off between controller objectives can be performed using different weights for these objectives to optimize torque ripples, phases currents, and switching frequency. The MPC can keep the torque $T_{e}$ close to reference signal $T_{\text {ref }}$, by predicting the future values of the phases torque and select the optimal switch state that will be applied to power converter switches to minimize the torque error. To minimize the copper loss in windings, due to current costs having an important effect, the difference between the actual values and the predicted values of the phases current should be taken into consideration and should be included in the cost function. Regarding the minimization of the average switching frequency, the switching times of the power converter's switches are used as the switching frequency indicator, and the predefined cost function should guarantee that a switch transition is delayed as much as possible to reduce the average switching frequency.

\subsection{SRM model}

The flux linkage of the SRM can be expressed as a function of the stator current $(I)$ and the rotor position angle $(\theta)$, this function is considered extremely nonlinear due to the SRM operates usually in the saturated zone. Generally, the magnetization characteristics of the SRM can be obtained using one of the following three ways:

- The first way is the experimental measurement, where the magnetization curve of the SRM can be measured using the flux equation. In this method, a suitable voltage source is applied to one stator winding of the SRM then the voltage and the current values are obtained and recorded, after that, the rotor position is changed and measure the voltage and current values, and repeat this process for each value of the rotor position angles, these measuring steps will be repeated for all motor phases. After processing the voltage and current waveforms of all phases of the motor, the magnetization curves of each phase can be obtained. The experimental measurement method is considered a very long process especially if the desired result needs to be accurate. Also, every process measures the characteristics of a single specific machine.

- The second way is the finite-element analysis. Based on the physical dimensions and characteristics of the SRM, such as lamination dimensions and magnetic characteristics, air gap length, stator and rotor poles arcs, and the size and number of turns of the stator windings, magnetization curve can be 
determined by applying the finite-element analysis method. Unfortunately, this information about physical dimensions and characteristics are not available from the manufacturer in most cases, but if you are designing the machine, you can easily get all the required specifications. Besides the lack of these specifications most of the time, this method is also considered a time-consuming process.

- The last way is the analytical expression. For control systems design purposes, it would be convenient and helpful to determine the magnetization curves from basic parameters, that can be measurable and manipulated easily, or can be mostly available. This method depends on the machine geometry and its standard construction. With the help of this method, the generic model of the SRM category having common basic parameters can be represented. In this work, the authors used that technique, and they are using the analytical model introduced in [34]. The Eqs. (1) to (9), which describe the analytical model used in this study, are discussed in details as following.

The magnetization curve at unaligned rotor position ( $q$ axis) is represented as a straight line with slope equal to the minimum inductance $L_{q}$ :

$\psi_{q}=L_{q} i$

The magnetization curve at the aligned rotor position ( $d$ axis) is a nonlinear function of the stator current $i$ :

$\psi_{d}=L_{d s a t} i+A\left(1-e^{-B i}\right)$,

where $L_{d s a t}$ is the $d$ axis saturated inductance, and $A$ and $B$ are constants determined by conditions at $i=0$ and $i=I_{m}$ ( $I_{m}$ is the maximum current in stator windings).

One has $e^{-B I m} \approx 0$ and the constants $A$ and $B$ can be deduced as:

$$
\begin{aligned}
& A=\psi_{m}-L_{d s a t} I_{m} \\
& B=\frac{L_{d}-L_{d s a t}}{\psi_{m}-L_{d s a t} I_{m}},
\end{aligned}
$$

where $L_{d}$ is the $d$ axis non-saturated inductance and $\psi_{m}$ is the flux linkage at $i=I_{m}$.

The interpolation between the two extremal curves with a suitable $\pi / 2$-periodic interpolation function is used to determine the magnetization curves for the intermediate points:

$$
f\left(\theta_{p}\right)=\left\{\begin{array}{c}
\frac{128 \theta^{3}}{\pi^{3}}-48 \frac{\theta_{p}^{2}}{\pi^{2}}+1, \text { if } \theta_{p} \in[0, \pi / 4] \\
f\left(\frac{\pi}{2}-\theta_{p}\right), \text { if } \theta_{p} \in[\pi / 4, \pi / 2]
\end{array} .\right.
$$

Consequently, the characteristics of the SRM 6/4 magnetization can be represented as:

$\left.\psi_{p}(i, \theta)=L_{q} i_{p}+L_{d s a t} i+A\left(1-e^{-B i_{p}}\right)-L_{q} i_{p}\right] f\left(\theta_{p}\right)$.

The electromagnetic torque produced by a phase $p$ is given by the derivative of the machine co-energy:

$T_{e, p}(i, \theta)=\left(\frac{\partial}{\partial \theta_{p}}\right) W_{p}{ }^{\prime}\left(i_{p}, \theta_{p}\right)$,

where $W$ is calculated as:

$W_{p}^{\prime}(i, \theta)=\int_{0}^{i_{p}} \psi\left(i_{p}, \theta_{p}\right) d i_{p}$.

Using $A$ and $B$, the analytical expression for the torque $T_{e}$ can be given by:

$T_{e, p}=\left[\frac{L_{d s a t}-L_{q}}{2} i_{p}^{2}+A i_{p}-\frac{A}{B}\left(1-e^{-B i_{p}}\right)\right] f^{\prime}\left(\theta_{p}\right)$.

Using the differential equation, the dynamics of the phase currents can be described as:

$\frac{d i_{p}}{d t}=\frac{1}{\frac{\partial \psi_{p}}{\partial i_{p}}}\left[U_{p}+R i_{p}-\frac{\partial \psi_{p}}{\partial \theta_{p}} \omega\right]$

\subsection{Controller design}

As mentioned earlier the significant advantage of MPC is the direct design procedure, thus the designer only needs to formulate a single function that includes all control objectives. In Subsection 3.2, the proposed PDITC scheme is illustrated in more detail. The block diagram of the PDITC method is described in Fig. 1, as it's known the DTC method needs electromagnetic reference torque $\left(T_{r e f}\right)$ signals to be tracked by motor's torque, so in some applications, a constant reference torque can be set, or in case of applications that required controllable speed such as EVs applications, the reference torque is generated using speed control loop, this speed control loop usually used linear controller.

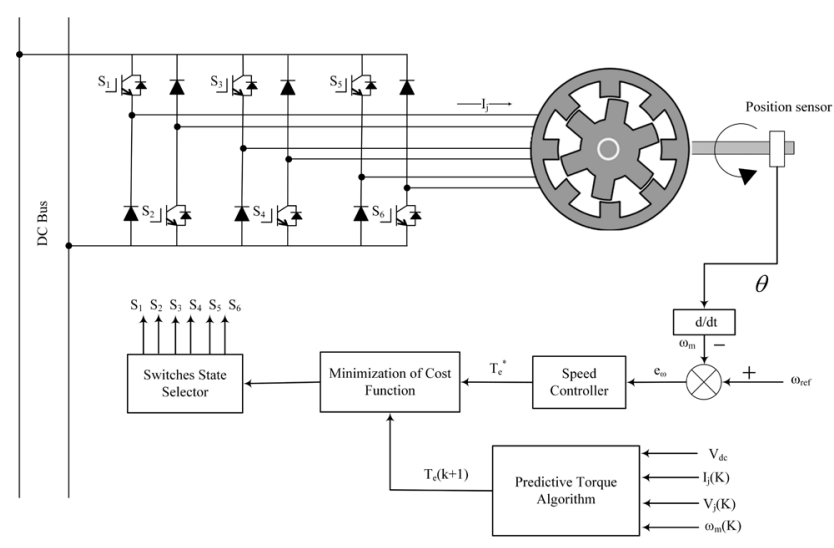

Fig. 1 Proposed PDITC block diagram of SRMs 
With the help of a predictive torque control algorithm, the future values of the total electromagnetic torques $T_{e}(k+1)$ can be predicted for all possible state by using the predictive model of the motor. These predicted values are assessed in a cost function with the other control objects, and then the optimal state that minimizes the cost function is selected, the gates signals will be selected for the optimal state and applied to the power converter switches in the next step. The combination of phases switching states is defined as a switching vector $S_{g}=\left[S_{1} S_{2} \ldots S_{j}\right]$, where $j$ is a number of the motor phases, depending on the number of phases of the motor and the number of switch states, the numbers of switching vectors $\mathrm{n}$ can be determined. For a three-phase SRM and with three states for each phase $\left(-V_{d c}, 0,+V_{d c}\right)$ the possible number of the switching vectors that can be applied to the power converter in each step are $n^{3}=27$, accordingly, there are 27 types of voltage vectors can be applied to the SRM.

The continuous-time model of the SRM can be replaced by a discrete-time model by applying forward Euler discretization as following.

The discrete-time expression of the phase currents is:

$i_{p}(k+1)=\left[\left(\frac{T_{s}}{\frac{\partial \psi_{p}}{\partial i_{p}(k)}}\right)\left(U_{p}(k)+R i_{p}(k)-\frac{\partial \psi_{p}}{\partial \theta_{p}} \omega\right)\right]+i_{p}(k)$.

And the discrete-time expression for the torque $T_{e}(k+1)$ can be given by:

$T_{e, p}(k+1)=$

$\left[\frac{L_{d s a t}-L_{q}}{2}\left(i_{p}(k+1)\right)^{2}+A i_{p}(k+1)-\frac{A}{B}\left(1-e^{-B i_{p}(k+1)}\right)\right]$

$f^{\prime}\left(\theta_{p}(k+1)\right)$,

where the next step value of the rotor position data can be estimated from the motor speed as:

$\theta_{p}(k+1)=\theta_{p}(k)+\omega T_{s}$.

In this study, the significant objective of the controller is to maintain the motor's torque close to the reference torque, which is usually set by a speed control loop, as mentioned before, with small ripples values. The further objectives that will be considered in the cost function are a reduction of the average switching frequency of the power converter and minimize the phases current lead to reduce the electrical losses in stator windings. By tuning and adjusting the different values of the weight factors for copper losses and average switching times in the cost function, the torque ripple, the electrical losses, and the average switching times can be optimized.

The average switching frequency of the power converter can be calculated from:

$F_{s w}=\frac{C_{1}+C_{2}+C_{3}}{3 T_{s}}$

where $C_{p}$ is the number of switches of the $P$ phase converter during a time interval $T_{s}$.

And the copper losses of the motor:

$P_{\text {loss }}=\sqrt{\frac{1}{N} \sum_{P=1}^{3} \sum_{k=1}^{N}\left(i_{k}\right)^{2} R}$

where $N$ is the number of samples.

The cost function $\mathrm{g}$ is calculated for all $n=27$ different voltage vectors $V_{g}$, as described earlier, and the voltage vector that minimizes cost function $\mathrm{g}$ will be applied to the motor in the next time interval. Eq. (15) describes the cost function that was used in this work:

$g=$

$\left|T_{e}^{*}-T_{e}(k+1)\right|+\lambda_{1} \sum_{j=1}^{3}\left|i_{j}(k+1)\right|+\lambda_{2}\left|S_{g}(k)-S_{g}(k-1)\right|$,

where $\lambda_{1}$ and $\lambda_{2}$ are the weight factors for copper losses and switching times respectively, where $1>\lambda_{1}>0$ and $1>\lambda_{2}>0$.

To demonstrate how the proposed PDITC algorithm works, the flowchart in Fig. 2 describes the steps of the proposed algorithm.

Firstly, measuring the phase current $i_{p}(k)$, DC bus voltage $V_{d c}(k)$, and motor speed $\omega_{m}$ or position data $\theta(k)$. In the meantime, reference values for the speed or torque of the motor should be set or generated. The second step is determining the magnetization characteristics of the 6/4 SRM are defined in Eq. (5). Then inside the iteration loop, apply the voltage vector $V_{g}(k)$ according to switching states in each cycle. In the third step estimation of the future values of the phases current $i_{p}(k+1)$ using Eq. (10), and the rotor position $\theta(k+1)$ Eq. (12), considering the applied voltage vector. The fourth step is the torque prediction step, predict the torque of the SRM for every possible voltage vector $T_{e}(\mathrm{k}+1)$ with $j=1, \ldots, 27$ using Eq. (11). Then evaluate the cost function g using Eq. (15) for each prediction. Finally, classify the different values of cost function from lower to higher and select the optimal state that provides the smallest value of the cost function, which generated from the optimal voltage vector, and return to the first step again. 


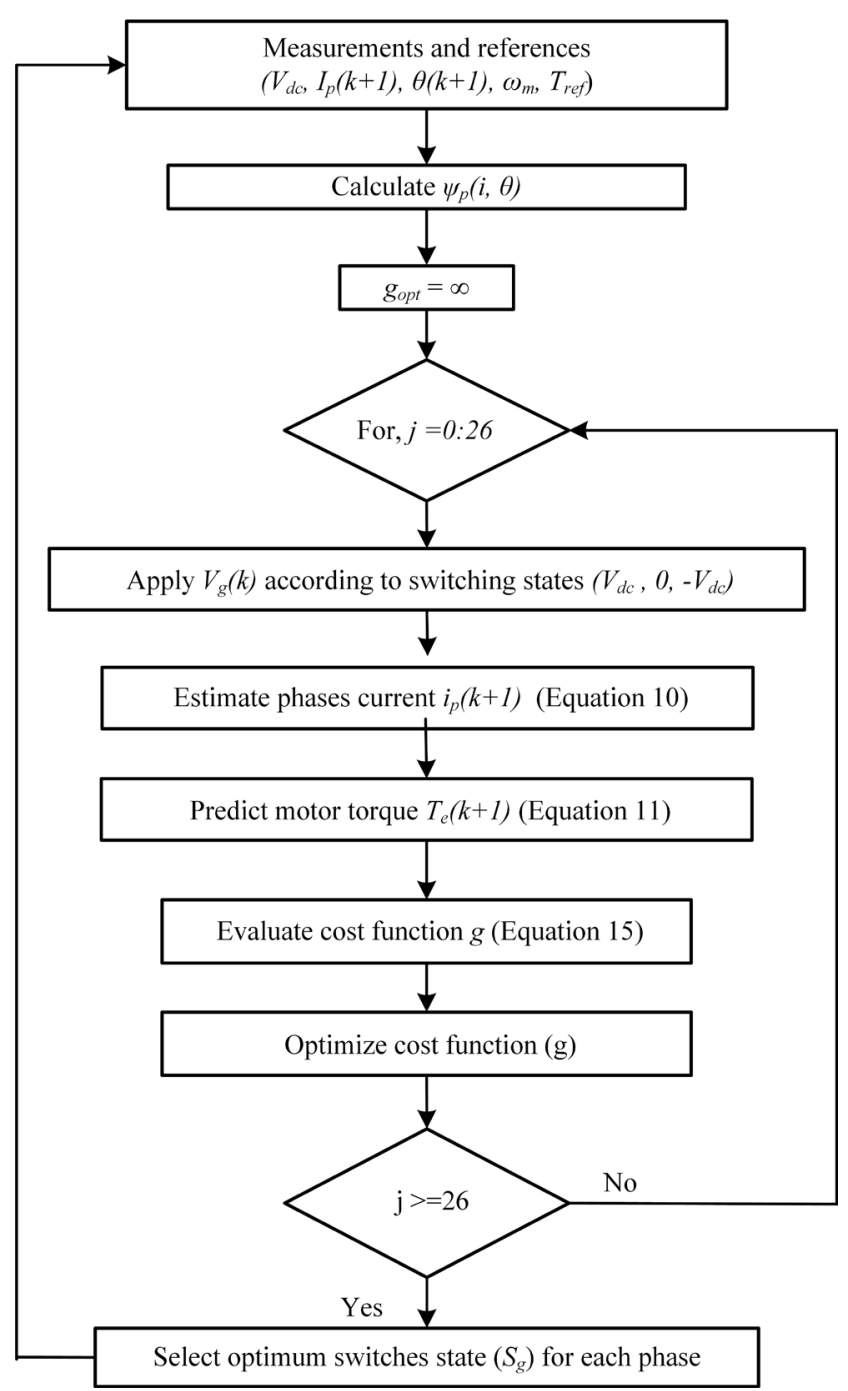

Fig. 2 Algorithm of the proposed PDITC

\section{Simulation results}

The impact of the introduced technique has been studied in Section 4 using a three-phase $4 / 6$ poles $60 \mathrm{~kW}$ nonlinear SRM. The simulation parameters of the motor are listed in Table $1[35,36]$.

In the simulation test, the step time was $10 \mu \mathrm{s}$, and the weights factors were set to $\lambda_{1}=0.025$ and $\lambda_{2}=0.002$.

Table 1 SRM simulation parameters

\begin{tabular}{|c|c|c|c|}
\hline Parameter & Value & Parameter & Value \\
\hline Power & $60 \mathrm{~kW}$ & $\begin{array}{l}\text { Max. flux linkage } \\
\left(\Psi_{m}\right)\end{array}$ & $0.486 \mathrm{~Wb}$ \\
\hline DC link voltage & $220 \mathrm{~V}$ & Speed & $1000 \mathrm{rpm}$ \\
\hline Max. Current (Im) & $450 \mathrm{~A}$ & Inertia & $0.05 \mathrm{~kg} \mathrm{~m}^{2}$ \\
\hline Stator resistance & $0.05 \Omega$ & $\begin{array}{c}\text { Aligned } \\
\text { inductance }\end{array}$ & $23.62 \mathrm{mH}$ \\
\hline Unaligned inductance & $0.67 \mathrm{mH}$ & No. of rotor pole & 4 \\
\hline $\begin{array}{l}\text { Saturated inductance } \\
\text { (Ldsat) }\end{array}$ & $0.15 \mathrm{mH}$ & No. of stator pole & 6 \\
\hline
\end{tabular}

To verify the performance and effectiveness of the proposed controller, the controller is tested with two different study cases. Also, a comparison was prepared between the proposed method and the traditional method. The first study case is investigating the controller robustness in following the reference torque, in this case, the SRM is running at the steady-state condition with a rotor speed of $n_{m}=1000 \mathrm{rpm}$ and the desired torque $T_{\text {ref }}=10 \mathrm{Nm}$, and at time $\mathrm{t}=0.3 \mathrm{~s}$, the desired torque makes a step to $T_{\text {ref }}=20 \mathrm{Nm}$. The simulation results obtained from the first case study using conventional DITC and proposed PDITC are shown in Fig. 3 and Fig. 4 respectively.
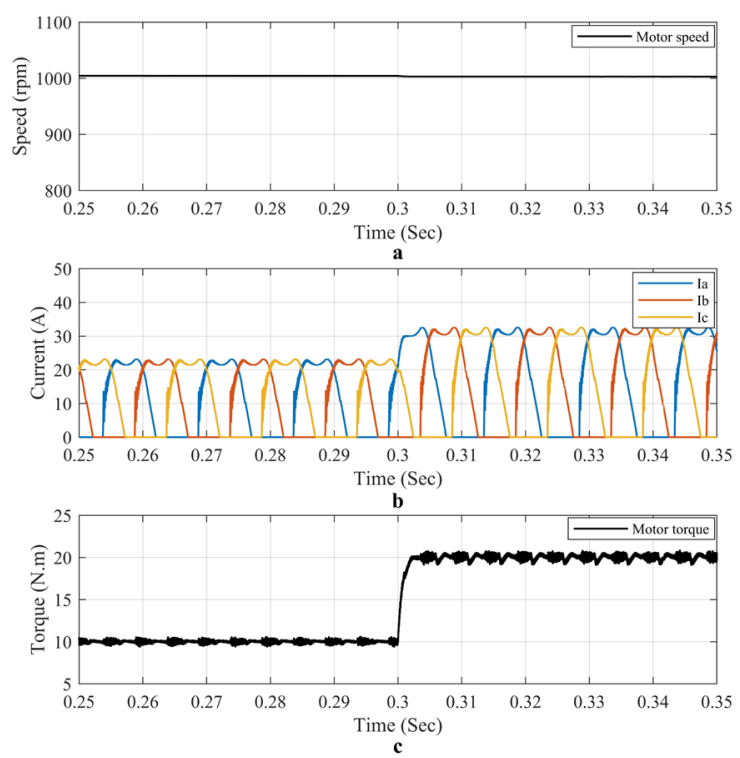

Fig. 3 Conventional DITC performance in the first case study
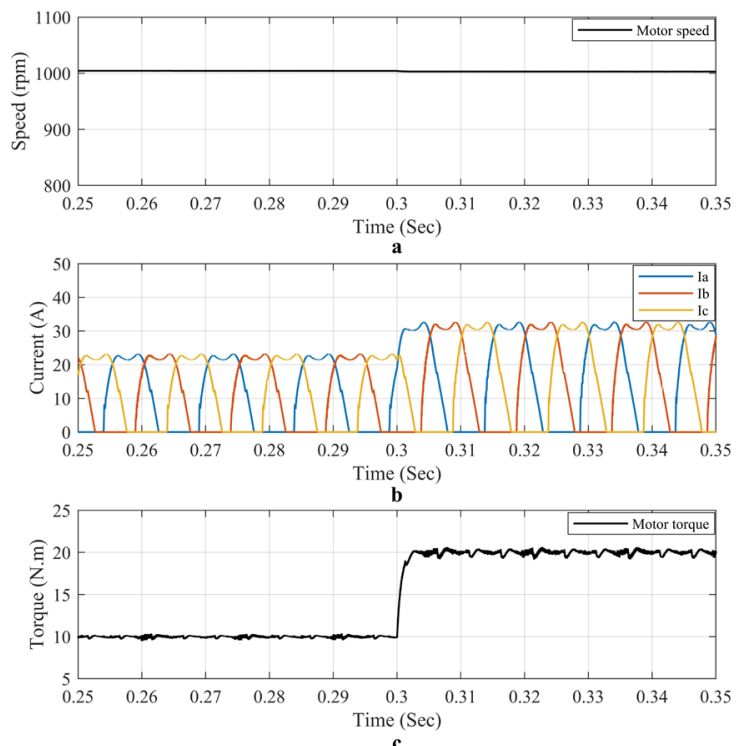

Fig. 4 Proposed PDITC performance in the first case study 
As can be seen from the obtained simulation results that the load torque changed at $\mathrm{t}=0.3 \mathrm{~s}$, the motor speed at steadystat in two control techniques exactly track the reference even if torque increases as shown in Fig. 3 (a) and Fig. 4 (a), this is thanks to the speed control loop. The three phases currents are switched $\mathrm{ON}$ and OFF according to the rotor position and torque control loop, due to the step-change in the load torque the current is rising up. From the motor toque signal, which shows in Fig. 3 (c) and Fig. 4 (c), it's clear that the motor torque ripples in case of using PDITC are smaller than the ripples using a conventional method. The detailed difference of the torque ripples value will be listed in a table and the enhancement in the torque performance will be discussed subsequently in the comparison section.

Regarding a second study case, which tests the tracking performances of the controller, the motor performance using conventional DITC is shown in Fig. 5, which load torque is $10 \mathrm{Nm}$ and the reference speed changed from 800 to $1200 \mathrm{rpm}$, and the motor performance in the case of PDITC is shown in Fig. 6. The motor speed is increasing from 800 to $1200 \mathrm{rpm}$ during $0.1 \mathrm{~s}$ to track the reference signal. As a result of the motor acceleration, the three-phase current is increasing also, and go back to normal value when the motor speed reaches the steady-state at $t=0.3 \mathrm{~s}$, as shown in Fig. 5 (b) and Fig. 6 (b). From the performance of the motor torque at steady-state speed condition, it is noted that the torque ripples using the proposed control method in Fig. 6 (c), whether in case of the motor speed is higher or smaller than the normal speed, are smaller than ripples in the case of using the conventional DITC method


Fig. 5 Conventional DITC performance in the second case study
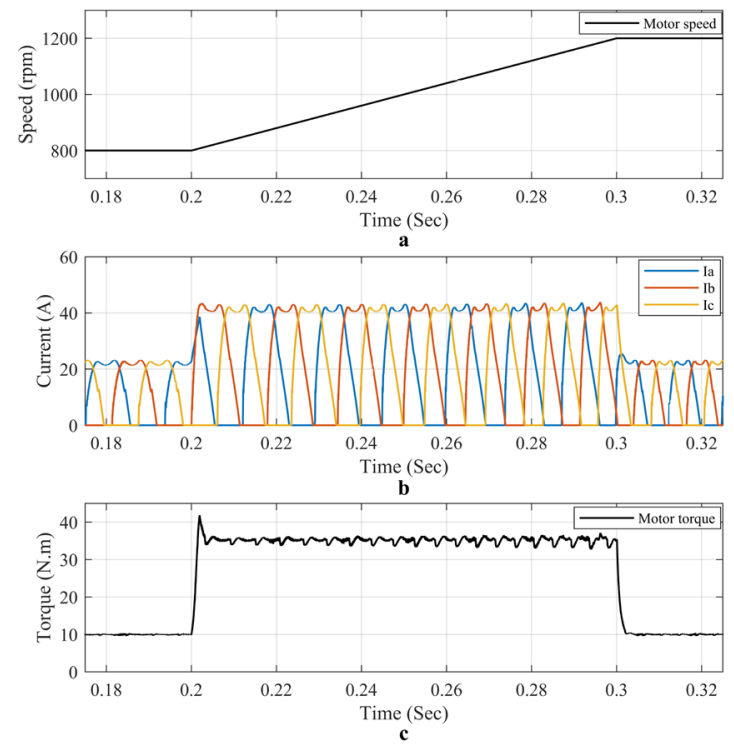

Fig. 6 Proposed PDITC performance in the second case study

in Fig. 5 (c). As the first study-case, the torque performance will be discussed and the detail torque ripples values using two different control techniques in all study cases will be listed and summarized in a comparison table.

Table 2 reviews and compares the torque ripples percentage, average switching frequency of the power converter, and copper losses using PDITC and conventional DITC, in case of different speed ranges with different load torque. As shown in the comparison table the traditional DITC technique has a torque ripple with a percentage of $13.5 \%, 14.25 \%$, and $14.8 \%$ at speed references 800,1000 , and $1200 \mathrm{rpm}$, respectively. While these percentages are reduced to $8.48 \%, 8.6 \%$, and $8.76 \%$ in the case of the proposed PDITC algorithm. Therefore, it can be seen that the proposed PDITC method has improved performance by $5 \%-6 \%$ compared with the traditional DITC technique. While this performance is improved by $2 \%-3 \%$ in the case of load torque has been doubled to $20 \mathrm{Nm}$. Table 2 also listed the average switching frequencies at load torque

Table 2 Comparison between the proposed PDITC and conventional DITC method at different speeds ranges

\begin{tabular}{lccccccc}
\hline & \multicolumn{3}{c}{$\begin{array}{c}\text { Torque ripples } \\
(\%)\end{array}$} & \multicolumn{2}{c}{$\begin{array}{c}\text { Switching } \\
\text { frequency }(\mathrm{Hz})\end{array}$} & \multicolumn{2}{c}{$\begin{array}{c}\text { Copper } \\
\text { losses }(\mathrm{W})\end{array}$} \\
\hline $\begin{array}{l}\mathrm{T}_{\mathrm{L}} \\
(\mathrm{Nm})\end{array}$ & $\begin{array}{c}\mathrm{n}_{\mathrm{m}} \\
(\mathrm{rpm})\end{array}$ & DITC & PDITC & DITC & PDITC & DITC & PDITC \\
& 800 & 13.5 & 8.48 & 6434 & 5163 & 27.25 & 27.01 \\
10 & 1000 & 14.25 & 8.6 & 6428 & 5091 & 27.265 & 27.1 \\
& 1200 & 14.8 & 8.76 & 5801 & 4732 & 27.3 & 27.13 \\
& 800 & 9.7 & 6.75 & 6812 & 5144 & 53.6 & 53.4 \\
20 & 1000 & 10 & 7.5 & 6056 & 4700 & 53.72 & 53.52 \\
& 1200 & 11.4 & 9.4 & 5255 & 4103 & 54.08 & 53.82 \\
\hline
\end{tabular}


$10 \mathrm{Nm}$ and for speeds 800,1000 , and $1200 \mathrm{rpm}$, which are 5163, 5091, and $4732 \mathrm{~Hz}$ in case of the proposed PDITC method and 6434, 6428 and $5801 \mathrm{~Hz}$ in case of the conventional DITC method. While when the load torque changes to $20 \mathrm{Nm}$, the value of the average switching frequencies became 5144, 4700, and $4103 \mathrm{~Hz}$ with PDITC method and 6812, 6056, and $5255 \mathrm{~Hz}$ using the conventional method. The data in Table 2 confirm that the copper losses are decreased, at different speed ranges, from 27.3 in the DITC method to 27.13 in the PDITC at $T_{L}=10 \mathrm{Nm}$, and from 54.08 in the DITC method to 53.82 in the PDITC at $T_{L}=20 \mathrm{Nm}$. Consequently, the copper losses for the proposed controller are lower by from $1 \%$ to $1.25 \%$ compared with the DITC technique. And this proves that the efficiency of SRM using the PDITC technique will be higher. The percentage of copper losses can be lower by increases the weighting factor of the phases current in controller objectives function $\left(\lambda_{1}\right)$, but this will affect the ripples values and the average switching frequency, and according to the application, the three controller objectives can be adjusted in the cost function by tuning the weighting factor of each objective to reach the optimal required performance.

\section{Conclusions}

In this study, the authors presented MPC based control method for the direct torque control of switched reluctance motors for electric vehicle applications, The MPC

\section{References}

[1] Vijayakumar, K., Karthikeyan, R., Paramasivam, S., Arumugam, R., Srinivas, K. N. "Switched Reluctance Motor Modeling, Design, Simulation, and Analysis: A Comprehensive Review", IEEE Transactions on Magnetics, 44(12), pp. 4605-4617, 2008. https://doi.org/10.1109/TMAG.2008.2003334

[2] Boldea, I., Tutelea, L. N., Parsa, L., Dorrell, D. "Automotive Electric Propulsion Systems With Reduced or No Permanent Magnets: An Overview", IEEE Transactions on Industrial Electronics, 61(10), pp. 5696-5711, 2014.

https://doi.org/10.1109/TIE.2014.2301754

[3] Abdel-Fadil, R., Számel, L. "State of the Art of Switched Reluctance Motor Drives and Control Techniques", In: 2018 Twentieth International Middle East Power Systems Conference (MEPCON), Cairo, Egypt, 2018, pp. 779-784.

https://doi.org/10.1109/MEPCON.2018.8635219

[4] Ilic'-Spong, M., Marino, R., Peresada, S., Taylor, D. "Feedback linearizing control of switched reluctance motors", IEEE Transactions on Automatic Control, 32(5), pp. 371-379, 1987.

https://doi.org/10.1109/TAC.1987.1104616

[5] Schramm, D. S., Williams, B. W., Green, T. C. "Torque ripple reduction of switched reluctance motors by phase current optimal profiling", In: PESC '92 Record. 23rd Annual IEEE Power Electronics Specialists Conference, Toledo, Spain, 1992, pp. 857-860.

https://doi.org/10.1109/PESC.1992.254793 is suitable for torque control of the SRM because it has many advantages. In the proposed control system, the exact analytical model is applied to predict the future sates of the control variables by using a nonlinear model from the literature to predict the nonlinear behavior of the SRM. At the same time, multiple control objectives are achieved by applying a predefined cost function, the main aim of the torque control is holding the torque close to the desired values with the smallest possible value for torque ripples, also the proposed controller aims to minimize the winding currents lead to decreases copper losses, and minimize the average switching frequency. In this paper, the C-programming language has been used to programmed the MPC algorithm, and the simulation model was conducted with $60 \mathrm{~kW}$ SRM. The proposed controller was studied at various loading conditions to investigate the controller robustness, and with variable reference speeds to examine the tracking performance of the proposed controller. The good performance obtained in simulations demonstrates the effectiveness of the proposed technique (PDITC) to minimize the torque ripples of the SRM, whether in case of torque load changed or in case of motor speed changed. With the help of PDITC, not only the torque tracks the reference signal with small values of ripples, but also the copper losses and the average switching frequency have been minimized compared to conventional DITC technique.

[6] Wallace, R. S., Taylor, D. G. "A balanced commutator for switched reluctance motors to reduce torque ripple", IEEE Transactions on Power Electronics, 7(4), pp. 617-626, 1992. https://doi.org/10.1109/63.163641

[7] Husain, I., Ehsani, M. "Torque ripple minimization in switched reluctance motor drives by PWM current control", Proceedings of 1994 IEEE Applied Power Electronics Conference and Exposition - ASPEC'94, Orlando, FL, USA, 1994, pp. 72-77. https://doi.org/10.1109/APEC.1994.316417

[8] Husain, I. "Minimization of torque ripple in SRM drives", IEEE Transactions on Industrial Electronics, 49(1), pp. 28-39, 2002. https://doi.org/10.1109/41.982245

[9] Cortes, P., Kazmierkowski, M. P., Kennel, R. M., Quevedo, D. E., Rodriguez, J. "Predictive Control in Power Electronics and Drives", IEEE Transactions on Industrial Electronics, 55(12), pp. 4312-4324, 2008. https://doi.org/10.1109/TIE.2008.2007480

[10] Eid, A., Abdel-Fadil, R., Abdel-Salam, M. "Performance and Power Quality Improvements of MEA Power Distribution Systems using Model Predictive Control", International Review of Aerospace Engineering (IREASE), 10(1), pp. 31-40, 2017. https://doi.org/10.15866/irease.v10i1.10998 
[11] Maciejowski, J. M. "Predictive control with constraints", Prentice Hall, Harlow, UK, 2002.

[12] Ahn, J. W. "Torque Control Strategy for High Performance SR Drive", Journal of Electrical Engineering and Technology, 3(4), pp. 538-545, 2008.

https://doi.org/10.5370/jeet.2008.3.4.538

[13] Ellabban, O., Abu-Rub, H. "Torque control strategies for a high performance switched reluctance motor drive system", In: 2013 7th IEEE GCC Conference and Exhibition (GCC), Doha, Qatar, 2013, pp. 257-262 https://doi.org/10.1109/IEEEGCC.2013.6705786

[14] Jebarani Evangeline, S., Suresh Kumar, S. "Torque ripple minimization of switched reluctance drives - a survey", In: 5th IET International Conference on Power Electronics, Machines and Drives (PEMD 2010), Brighton, UK, 2010, pp. 1-6. https://doi.org/10.1049/cp.2010.0177

[15] Choi, C., Kim, S., Kim, Y., Park, K. "A new torque control method of a switched reluctance motor using a torque-sharing function", IEEE Transactions on Magnetics, 38(5), pp. 3288-3290, 2002. https://doi.org/10.1109/TMAG.2002.802295

[16] Xue, X. D., Cheng, K. W. E., Ho, S. L. "Optimization and Evaluation of Torque-Sharing Functions for Torque Ripple Minimization in Switched Reluctance Motor Drives", IEEE Transactions on Power Electronics, 24(9), pp. 2076-2090, 2009. https://doi.org/10.1109/TPEL.2009.2019581

[17] Ye, J., Bilgin, B., Emadi, A. "An Offline Torque Sharing Function for Torque Ripple Reduction in Switched Reluctance Motor Drives", IEEE Transactions on Energy Conversion, 30(2), pp. 726-735, 2015. https://doi.org/10.1109/TEC.2014.2383991

[18] Vujičić, V. P. "Minimization of Torque Ripple and Copper Losses in Switched Reluctance Drive", IEEE Transactions on Power Electronics, 27(1), pp. 388-399, 2012. https://doi.org/10.1109/TPEL.2011.2158447

[19] Kjaer, P. C., Gribble, J. J., Miller, T. J. E. "High-grade control of switched reluctance machines", IEEE Transactions on Industry Applications, 33(6), pp. 1585-1593, 1997. https://doi.org/10.1109/28.649972

[20] Lee, D. H., Liang, J., Lee, Z. G., Ahn, J. W. "A Simple Nonlinear Logical Torque Sharing Function for Low-Torque Ripple SR Drive", IEEE Transactions on Industrial Electronics, 56(8), pp. 3021-3028, 2009. https://doi.org/10.1109/TIE.2009.2024661

[21] Cheok, A. D., Fukuda, Y. "A new torque and flux control method for switched reluctance motor drives", IEEE Transactions on Power Electronics, 17(4), pp. 543-557, 2002. https://doi.org/10.1109/TPEL.2002.800968

[22] Inderka, R. B., De Doncker, R. W. A. A. "DITC-direct instantaneous torque control of switched reluctance drives", IEEE Transactions on Industry Applications, 39(4), pp. 1046-1051, 2003.

https://doi.org/10.1109/TIA.2003.814578

[23] Fuengwarodsakul, N. H., Menne, M., Inderka, R. B., De Doncker, R. W. "High-dynamic four-quadrant switched reluctance drive based on DITC", IEEE Transactions on Industry Applications, 41(5), pp. 1232-1242, 2005.

https://doi.org/10.1109/TIA.2005.853381
[24] Gan, C., Wu, J., Sun, Q., Yang, S., Hu, Y., Jin, L. "Low-cost direct instantaneous torque control for switched reluctance motors with bus current detection under soft-chopping mode", IET Power Electronics, 9(3), pp. 482-490, 2016.

https://doi.org/10.1049/iet-pel.2015.0370

[25] Ronanki, D., Williamson, S. S. "Comparative analysis of DITC and DTFC of switched reluctance motor for EV applications", In: 2017 IEEE International Conference on Industrial Technology (ICIT), Toronto, ON, Canada, 2017, pp. 509-514. https://doi.org/10.1109/ICIT.2017.7913284

[26] Hu, Y., Ding, W. "Study on energy ratio of switched reluctance motor drive based on open loop, CCC and DITC", In: 2016 Eleventh International Conference on Ecological Vehicles and Renewable Energies (EVER), Monte Carlo, Monaco, 2016, pp. 1-6. https://doi.org/10.1109/EVER.2016.7476344

[27] Petrus, V., Pop, A. C., Martis, C. S., Iancu, V., Gyselinck, J. "Direct instantaneous torque control of SRMs versus current profiling - Comparison regarding torque ripple and copper losses", In: 2012 13th International Conference on Optimization of Electrical and Electronic Equipment (OPTIM), Brasov, Romania, 2012, pp. 366-372. https://doi.org/10.1109/OPTIM.2012.6231849

[28] Peyrl, H., Papafotiou, G., Morari, M. "Model predictive torque control of a Switched Reluctance Motor", In: 2009 IEEE International Conference on Industrial Technology, Gippsland, VIC, Australia, 2009, pp. 1-6. https://doi.org/10.1109/ICIT.2009.4939734

[29] Abdel-Fadil, R., Számel, L. "Enhancement Of the Switched Reluctance Motor Performance for Electric Vehicles Applications Using Predictive Current Control", In: 2018 International IEEE Conference and Workshop in Óbuda on Electrical and Power Engineering (CANDO-EPE), Budapest, Hungary, 2018, pp. 000195-000200. https://doi.org/10.1109/CANDO-EPE.2018.8601168

[30] Villegas, J., Vazquez, S., Carrasco, J. M., Gil, I. "Model Predictive Control of a switched reluctance machine using discrete Space Vector Modulation", In: 2010 IEEE International Symposium on Industrial Electronics, Bari, Italy, 2010, pp. 3139-3144. https://doi.org/10.1109/ISIE.2010.5637881

[31] Li, X., Shamsi, P. "Inductance Surface Learning for Model Predictive Current Control of Switched Reluctance Motors", IEEE Transactions on Transportation Electrification, 1(3), pp. 287-297, 2015 https://doi.org/10.1109/TTE.2015.2468178

[32] Li, X., Shamsi, P. "Model Predictive Current Control of Switched Reluctance Motors With Inductance Auto-Calibration", IEEE Transactions on Industrial Electronics, 63(6), pp. 3934-3941, 2016. https://doi.org/10.1109/TIE.2015.2497301

[33] Li, C., Wang, G., Li, Y., Xu, A. "An improved finite-state predictive torque control for switched reluctance motor drive", IET Electric Power Applications, 12(1), pp. 144-151, 2018. https://doi.org/10.1049/iet-epa.2017.0268 
[34] Le-Huy, H., Brunelle, P. "A versatile nonlinear switched reluctance motor model in Simulink using realistic and analytical magnetization characteristics", In: 31st Annual Conference of IEEE Industrial Electronics Society, Raleigh, NC, USA, 2005, pp. 1556-1561. https://doi.org/10.1109/IECON.2005.1569136

[35] Abdel-Fadil, R. M., Számel, L. "Direct Instantaneous Torque Control of the Switched Reluctance Motor for Electric Vehicles Applications Using Fuzzy Logic Control", Acta Technica Jaurinensis, 12(2), pp. 101-116, 2019.

https://doi.org/10.14513/actatechjaur.v12.n2.496
[36] Saha, N., Panda, S. "Speed control with torque ripple reduction of switched reluctance motor by Hybrid Many Optimizing Liaison Gravitational Search technique", Engineering Science and Technology, an International Journal, 20(3), pp. 909-921, 2017. https://doi.org/10.1016/j.jestch.2016.11.018 